\title{
Optimization of the tribological performance of rectangular seals in automotive transmissions
}

\author{
M Gronitzki and G W G Poll* \\ Institute of Machine Elements, Engineering Design and Tribology, Hannover University, Hannover, Germany \\ The manuscript was received on 18 September 2006 and was accepted after revision for publication on 8 February 2007.
}

DOI: $10.1243 / 13506501 J E T 247$

\begin{abstract}
Rectangular seals - a special type of face seals - are currently used in rotating connections of automatic automotive transmissions (double clutch transmissions, continuously variable transmissions, and 6-automated transmission) for the oil pressure supply of rotating control and actuator elements. Friction losses of several kilowatts can occur in the sealing system, causing a considerable reduction in efficiency. As a result of ongoing progress in power train design, sliding speeds and fluid pressures continue to increase. Therefore, due to friction related temperature rise in the sealing contact, extensive oil carbonization may occur. For both the reasons, developing friction optimized seals is crucial.

For cost and design reasons grey cast iron rings are more and more substituted by modern, high temperature resistant thermoplastics. These materials also exhibit better friction and wear performance which can further be improved by adding polytetrafluorethylen or graphite.

Because of their lower stiffness compared with metallic components, special thoughts have to be given to the design of thermoplastic rectangular seals. This paper describes how an improved geometry with optimized friction and wear performance was achieved by combining experimental investigations and numerical calculations on thermomechanical deflections.
\end{abstract}

Keywords: rectangular seals, automotive transmission, high temperature plastics

\section{INTRODUCTION}

At the beginning of the nineties only manual or automated stepped transmissions with planetary gears and hydrodynamic torque converter were available for passenger cars. Today, a variety of transmission types are in series production. Among those are automated manual transmissions, double clutch transmissions (DCT), continuously variable transmissions (CVT) in different designs and modern automated transmissions with up to seven gear ratios. It is expected that the market share of these transmission types will increase.

Most of these transmissions contain rotating actuators which are activated by means of pressurized oil. In most cases one or several sealed connections

\footnotetext{
${ }^{*}$ Corresponding author: Institute of Machine Elements, Engineering Design and Tribology, Hannover University, Welfengarten 1A, Hannover D-30167, Germany. email: poll@imkt.uni-hannover.de
}

exist for the oil transfer from the stationary parts into the rotating shaft. These rotating connections have to sustain pressures up to $2.5 \mathrm{MPa}$ in automated transmission (AT) and up to $8 \mathrm{MPa}$ in CVT-applications. At shaft speeds up to $7500 \mathrm{r} / \mathrm{min}$ and shaft diameters of up to $80 \mathrm{~mm}$ power losses of more than $1 \mathrm{~kW}$ can occur. These reduce the efficiency of the transmission and lead to a high thermal stress of the seal and the sealed fluid.

Rectangular seal rings are commonly used in those rotating connections; they are located between the shoulder of a groove in the rotating shaft and the surrounding housing and direct the oil radially into the transmission shaft. The seal design is quite similar to piston rings but instead of a reciprocating motion the seal rotates. The sliding movement can take place at the side face or at the circumference of the seal. Usually no positive interlocking or strong enough press fit exists between the seal and the surrounding parts which would prevent a relative rotation.

Originally grey cast iron alloys were used as sealing ring material. Polytetrafluorethylen (PTFE) and 


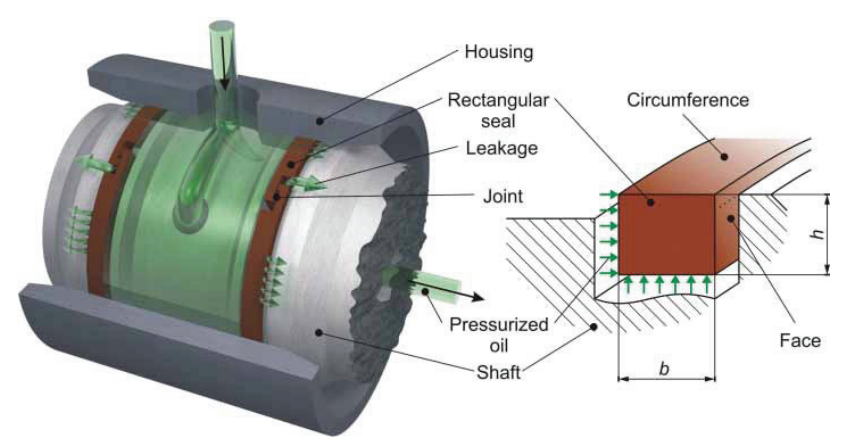

Fig. 1 Design of the sealing system

ethylene-tetrafluorethylene (ETFE) were introduced for the first time at the beginning of the nineties; they were replaced later on by high temperature resistent plastics (ht-plastics) such as polyetheretherketon (PEEK), polyamidimid (PAI), polyimid, and thermoplastic polyimide (TPI). Some of these materials are able to operate permanently at temperatures up to $300{ }^{\circ} \mathrm{C}$ [1-3] (Fig. 1).

In order to mount the seals in the groove on the shaft it is necessary to expand them to the shaft outer diameter. For this purpose they are provided with a joint which also compensates tolerances of diameter, wear and thermal changes of length during operation. This joint causes a considerably higher leakage than the remaining parts of the sealing system, but, as the oil remains in the transmission and does not leak into the environment, such a leakage is tolerable within limits. In order to minimize leakage through the joint, a number of different designs with narrow gaps and multiple baffles were developed [1].

Compared to most mechanical face seals this seems to be a fairly simple system; however, to ensure proper and reliable functioning as well as high efficiency detailed knowledge of the mechanisms involved is required. However, so far, rectangular shaft seals have rarely been the subject of in-depth research, a fact which inspired the investigations, part of which is presented in this paper.

\section{EXPERIMENTAL SETUP}

\subsection{Test equipment}

For the experimental investigation of rectangular seal rings in rotating connections a test rig was designed and built at the Institute for Machine Elements, Engineering Design and Tribology of Hanover University which permits tests and measurements under conditions which closely reflect real operation (Fig. 2). In contrast to real transmissions, however, it allows measuring various parameters such as friction torque, friction induced temperature rise and leakage. The structure of the test chamber is modular and can be adapted to different designs of rotating connections.

The torque is measured by strain gauges on a measuring shaft, which is located between the test spindle and the drive shaft. In order to determine leakage an automated balance is placed underneath the test cell to which the leakage oil is supplied through several valves.

Temperatures are recorded at several locations. The temperature of the housing $\left(T_{0}\right)$ is measured between the channels for pressure supply and heating. In a distance of $0.5 \mathrm{~mm}$ to the wall of the housing, temperature sensors are placed close to each seal ring $\left(T_{1}, T_{2}\right) . T_{5}$ and $T_{6}$ represent the temperatures of the oil in- and outlet respectively. Into the seals axial counterface two thermocouples which are only $0.3 \mathrm{~mm}$ thick are embedded at different radii; the surface is

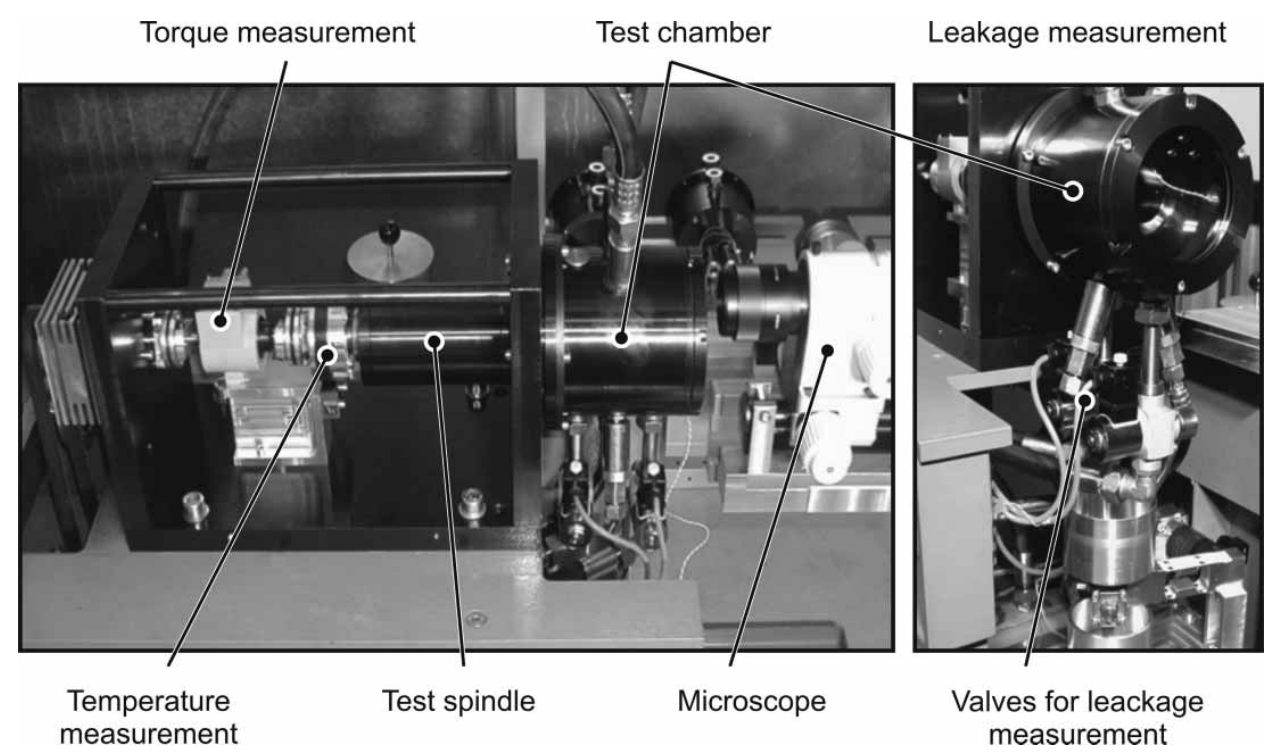

Fig. 2 Test rig for experimental investigations 


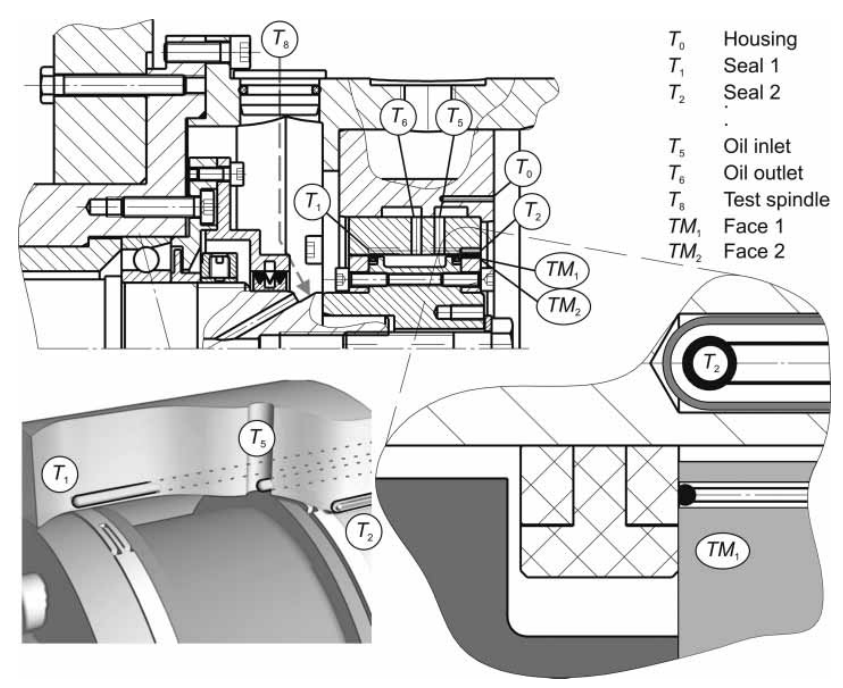

Fig. 3 Temperature measurement

subsequently finished by grinding. $T M_{1}$ is close to the shaft's outer diameter whereas $T M_{2}$ is shifted towards the seal's inner diameter (Fig. 3).

As pointed out before, it is not known a priori where the relative motion occurs. By comparing the temperatures at the axial and radial sealing areas one can identify the contact with the significantly higher amount of sliding. A quantitative determination of the seals rotational speed is possible by means of a photoelectric sensor which detects the passage of the seal ring joint via a fibreglass light guide.

\subsection{Test conditions}

The rotating connection and the operating conditions selected for the investigations presented here are typical for current DCT applications:

(a) Nominal diameter: $56 \mathrm{~mm}$; (b) Rotation speed: up to $7000 \mathrm{r} / \mathrm{min}(20.5 \mathrm{~m} / \mathrm{s})$;

(c) Pressure: 0.1-3 MPa, max. $5 \mathrm{MPa}$.

\subsection{Seals}

Seals out of different ht-plastics, but with identical geometry were investigated, as well as another type of seal made from grey cast iron. Table 1 contains a brief overview of the material properties. Although PEEK is a semicrystalline material PAI has a purely amorphous structure.

The base polymers are filled with PTFE or graphite in order to improve friction and processing properties. The PEEK B compound is reinforced with glass and carbon fibres and has a significantly enhanced stiffness combined with reduced elongation at break compared to the base polymer.

\section{RESULTS}

\subsection{Friction loss}

The friction loss in a rotating connection originates partly from the seals themselves and partly from shearing pressurized oil in the gaps between housing and shaft surface. Especially at large circumferential speeds, the latter cause contributes substantially to the total friction torque.

\subsubsection{Friction torque and seal movement}

As pointed out before, in contrary to most other seal designs it is not strictly predetermined at which surface the seal will slide. Sliding motions relevant for friction losses can therefore occur either at the axial face or at the circumference of the seal or even at both locations simultaneously; then, the seal rotates at a speed lower than the speed of the shaft.

Table 1 Properties of sealing materials used for the investigations

\begin{tabular}{|c|c|c|c|c|c|}
\hline Seal material & $\begin{array}{l}\text { PEEK A } \\
1515\end{array}$ & $\begin{array}{l}\text { PEEK B } \\
150 F C 30\end{array}$ & $\begin{array}{l}\text { PAI A } \\
4203 \mathrm{~L}\end{array}$ & $\begin{array}{l}\text { PAI B } \\
4301\end{array}$ & $\begin{array}{l}\text { Grey cast } \\
\text { iron }\end{array}$ \\
\hline PTFE (\%) & 15 & 10 & 5 & 3 & - \\
\hline Graphite (\%) & 15 & - & - & 12 & - \\
\hline Glass fibre (\%) & - & 10 & - & - & - \\
\hline Carbon fibre (\%) & - & 10 & - & - & - \\
\hline $\begin{array}{l}\text { Tensile strength at } 20^{\circ} \mathrm{C} \\
\left(\mathrm{N} / \mathrm{mm}^{2}\right)\end{array}$ & 70 & 137 & 192 & 164 & 600 \\
\hline $\begin{array}{l}\text { Young's modulus at } 20^{\circ} \mathrm{C} \\
\left(\mathrm{N} / \mathrm{mm}^{2}\right)\end{array}$ & 4000 & 11200 & 4900 & 6600 & 120000 \\
\hline $\begin{array}{l}\text { Elongation at break at } \\
20^{\circ} \mathrm{C}(\%)\end{array}$ & 4 & 1.8 & 15 & 7 & 0.5 \\
\hline Gravity $\left(\mathrm{kg} / \mathrm{m}^{3}\right)$ & 1.490 & 1.440 & 1.420 & 1.460 & 7.200 \\
\hline $\begin{array}{l}\text { Glass transition } \\
\text { temperature }\left({ }^{\circ} \mathrm{C}\right)\end{array}$ & 143 & 143 & 285 & 285 & - \\
\hline Thermal elongation $(1 / \mathrm{K})$ & $5.0 \cdot 10^{-5}$ & $2.2 \cdot 10^{-5}$ & $3.06 \cdot 10^{-5}$ & $2.52 \cdot 10^{-5}$ & $1.1 \cdot 10^{-5}$ \\
\hline $\begin{array}{l}\text { Heat conductivity } \\
(\mathrm{W} /(\mathrm{mK}))\end{array}$ & 0.25 & 0.78 & 0.26 & 0.54 & 50 \\
\hline Thermal capacity $(\mathrm{J} /(\mathrm{kgK}))$ & k.A. & 1800 & 1000 & 1000 & 600 \\
\hline
\end{tabular}




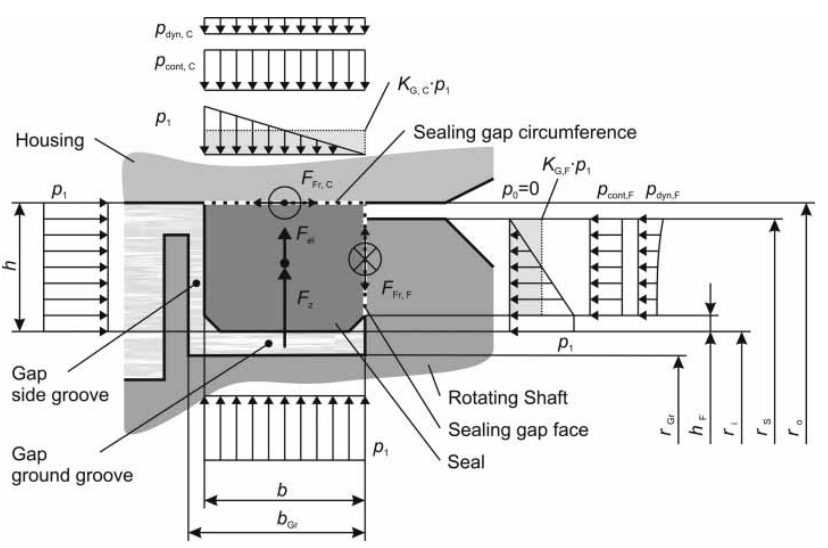

Fig. 4 Forces action on a rectangular seal ring

A simple model suffices to describe the underlying kinetics: the maximum friction torque $M_{\mathrm{F}, \mathrm{C}}$ and $M_{\mathrm{F}, \mathrm{F}}$ that can be transmitted by the contact areas is compared at low speeds. Sliding concentrates at the contact with the lower torque.

In order to determine the friction torques the balance of forces acting on a seal ring needs to be considered, Fig. 4.

In the axial direction the hydraulic force caused by the pressure, $p_{1}$, acts on the side of the seal. At the opposite side the forces are supported by the median contact pressure $p_{\mathrm{cont}, \mathrm{F}}$ and the hydraulic pressure in the gap which consists of a static portion $p_{\mathrm{cont,F}}$ caused by the pressure profile in the gap and possibly a hydrodynamic portion $p_{\mathrm{dyn}, \mathrm{F}}$, as consequence of the tangential fluid flow. Both act on the annular axial seal surface except the gap between housing and shaft. The force ratio between both surfaces can be derived from the balance ratio

$$
k_{\mathrm{F}}=\frac{A_{1}}{A}=\frac{r_{\mathrm{o}}^{2}-\left(r_{\mathrm{i}}+h_{\mathrm{F}}\right)^{2}}{r_{\mathrm{S}}^{2}-\left(r_{\mathrm{i}}+h_{\mathrm{F}}\right)^{2}}
$$

It is assumed that the medium pressure resulting from the dropping pressure profile in the gap is proportional to the sealed pressure $\left(K_{\mathrm{G}, \mathrm{F}} \cdot p_{1}\right)$. If the gap is parallel the pressure declines almost linear. The factor $K_{\mathrm{G}, \mathrm{F}}$ becomes 0.5 . In the case of a convergent gap the fluid pressure is able to penetrate further into the gap so that the load at the sliding face is reduced $\left(K_{\mathrm{G}} \rightarrow 1\right)$. If the gap is divergent the effect is reverse $\left(K_{\mathrm{G}} \rightarrow 0\right)$.

The contact pressure at the face and the corresponding friction torque can now be calculated as follows

$$
\begin{aligned}
& p_{\text {cont }, \mathrm{F}}=p_{1} \cdot\left(k_{\mathrm{F}}-K_{\mathrm{G}, \mathrm{F}}\right)-p_{\mathrm{dyn}, \mathrm{F}} \\
& M_{\mathrm{F}}=f_{\mathrm{F}}(G) \cdot \int_{r_{\mathrm{i}}+h_{\mathrm{f}}}^{r_{\mathrm{f}}} \int_{0}^{2 \pi} p_{\text {cont } \mathrm{F}} \cdot r^{2} \mathrm{~d} \varphi \mathrm{d} r \\
& M_{\mathrm{F}}=\frac{2}{3} \pi \cdot f_{\mathrm{F}}(G) \cdot\left(r_{\mathrm{S}}^{3}-\left(r_{i}+h_{\mathrm{F}}\right)^{3}\right) \cdot p_{\text {cont }, \mathrm{F}}
\end{aligned}
$$

The contact pressure and the friction torque at the circumference can be computed in a similar way

$$
\begin{aligned}
& k_{\mathrm{C}}=\frac{b \cdot r_{\mathrm{i}}+b_{\mathrm{F}} \cdot h_{\mathrm{F}}}{b \cdot r_{\mathrm{o}}} \\
& p_{\mathrm{cont}, \mathrm{C}}=p_{1} \cdot\left(k_{\mathrm{C}}-K_{\mathrm{G}, \mathrm{C}}\right)-p_{\mathrm{dyn}, \mathrm{C}}+\frac{F_{\mathrm{Z}}+F_{\mathrm{el}}}{2 \pi \cdot b \cdot r_{\mathrm{o}}} \\
& M_{\mathrm{C}}=f_{\mathrm{C}}(G) \cdot \int_{0}^{b} \int_{0}^{2 \pi} p_{\mathrm{Cont}, \mathrm{C}} \cdot r^{2} \mathrm{~d} \varphi \mathrm{d} b \\
& M_{\mathrm{C}}=f_{\mathrm{C}}(G) \cdot 2 \pi \cdot r_{\mathrm{o}}^{2} \cdot b \cdot p_{\text {cont } \mathrm{C}}
\end{aligned}
$$

Assuming the same coefficients of friction at both contact areas, the seal rotation would only depend on the geometry of the shaft and the seal as well as on the gap geometry in both contacts. Figure 5 shows the expected mode of motion as a function of the seal cross-section.

Accordingly, at a shaft diameter of $d_{\mathrm{S}}=55.5 \mathrm{~mm}$ and a square cross-section, in theory the sliding motion should exclusively occur at the circumferential surface of the seal, which is usually not the preferred mode of operation. In order to prevent a rotation of the seal with respect to the housing, the ratio of width and height has to be increased to $b / h=1.22$.

In the most common case of a converging gap at the axial face, a smaller seal width may be chosen. The same result may be achieved by reducing the gap between housing at shaft; however, there are limitations because of geometrical imperfections such as dynamic runout, shaft to bore misalignment and unequal thermal expansion.

Generally, either mode of operations may make sense. An important criterion is a sufficient heat transfer from the sliding surfaces which depends on the heat flow through the surrounding parts as well as on the convection through the fluid. Converging gaps offer the advantage of a better cooling by the fluid and a relief of the seal. As they are more likely to form at the axial face than on the circumference of sealing

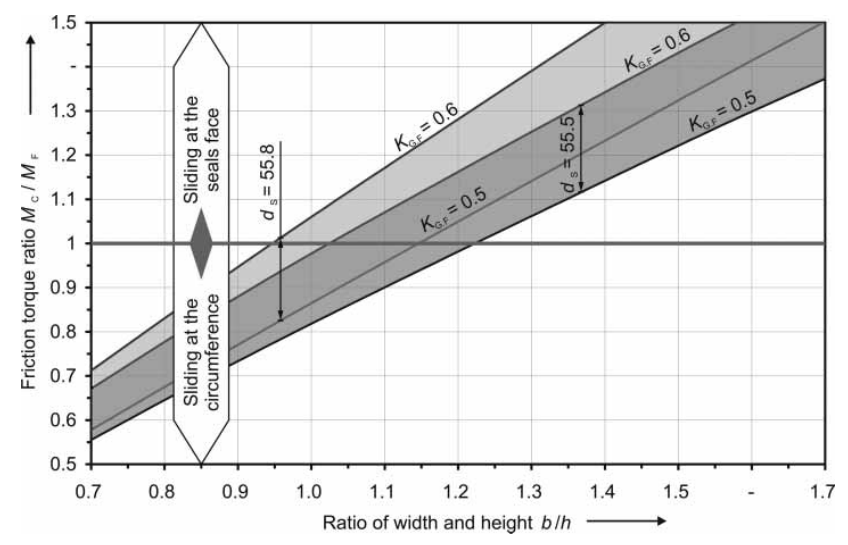

Fig. 5 Friction torque ratio 
rings there is a preference for an axial sliding contact in most applications.

\subsubsection{Creep rotation}

The experimental investigations focused on seals which are intended to rotate relatively to the shaft. In reality, however, those seals were found to rotate relatively to the housing as well, albeit at low speed. This was already observed earlier by other authors, e.g. Rogler [4], but attributed to small radial movements of shaft. Instead, it became obvious that oscillating axial movements between shaft and sealing ring help to overcome static friction and thus add a circumferential component to sliding velocity. The axial motions are imposed by axial runout of both the sealing ring face and the shoulder of the groove in the shaft. Such geometrical imperfections are always present to some extent (Fig. 6).

\subsubsection{Calculations on temperature distribution and seal deformations}

The operating limit of rotary shaft seals is often given by the temperature in the sealing zone. Either the fluid which has to be sealed may evaporate or be pyrolized or the solid materials may loose properties required for proper functioning. The temperature in the sealing gap is determined by the frictional heat generated in
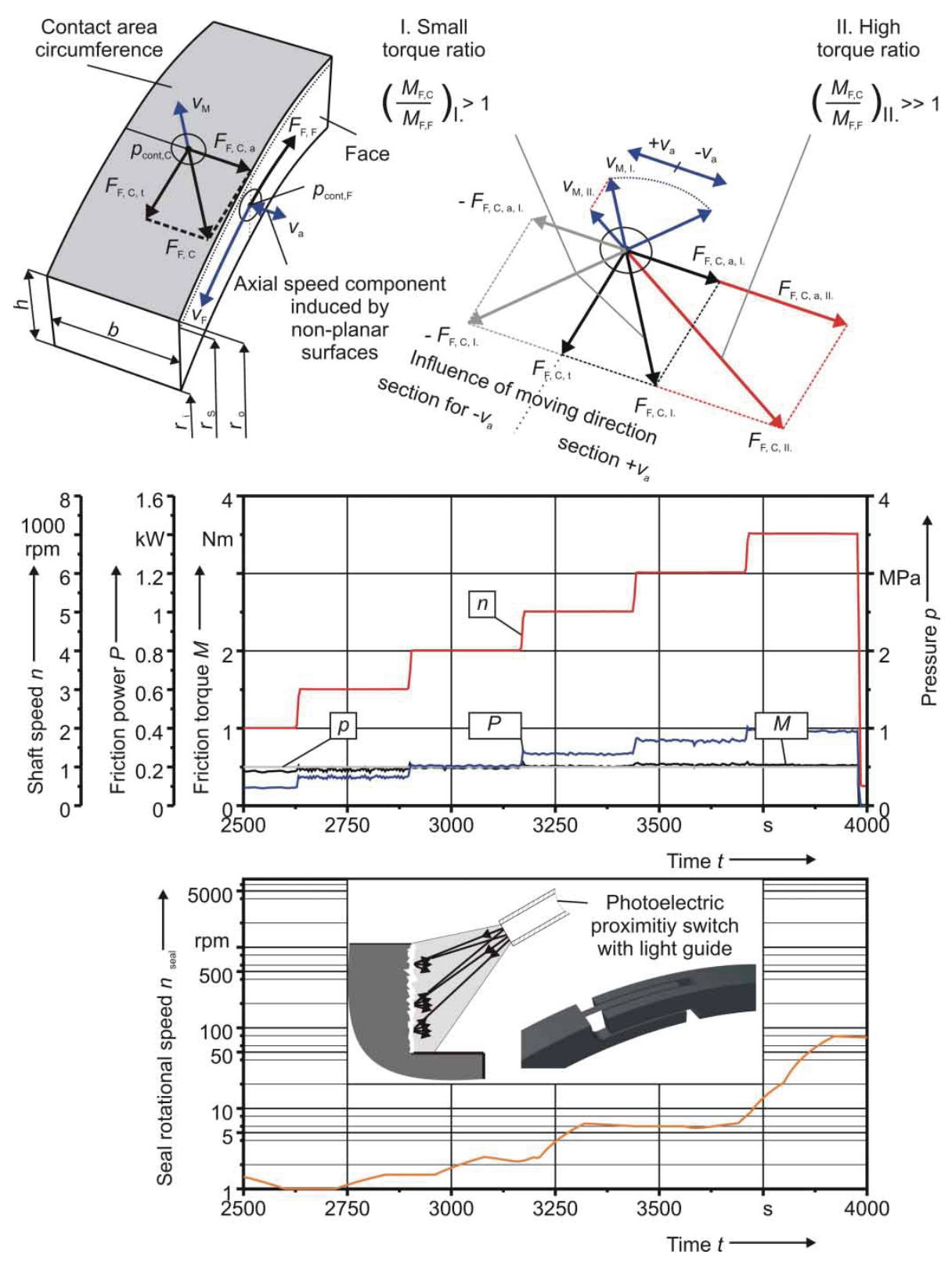

Fig. 6 Creep rotation, theoretical model, and measurement 

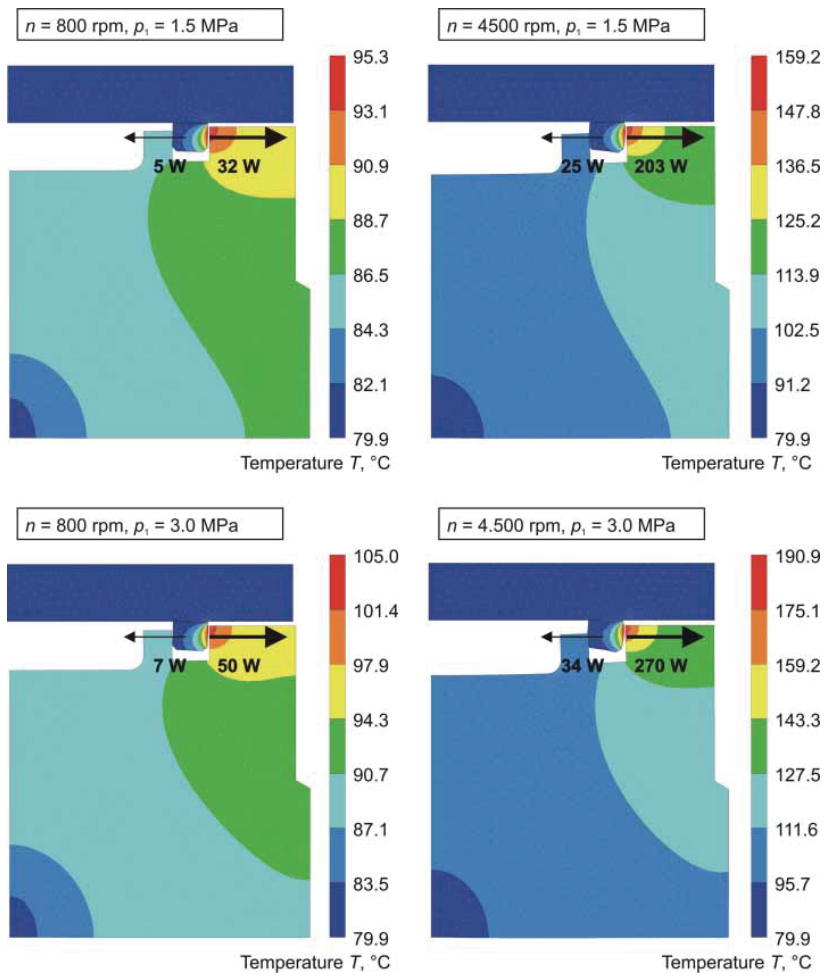

Fig. 7 Calculated deformations and temperature distributions (seal material PEEK A)

the contact zone and its dissipation into surrounding parts and the fluid.

A close examination of the forces acting on a rectangular seal reveals that apart from operating conditions and geometry it is above all the gap shape formed between the sliding sealing surfaces during operation at the sliding sealing which dominates the friction losses. In contrary to Fig. 4 the gap in the sealing contact always deviates from the hypothetical parallel shape due to thermomechanical deformations of the seal and the shaft.

These deformations were studied by modifying the finite-element package SEALHDLN* originally created by A. Lebeck at MSTI, for the analysis of mechanical face seals. It is designed to perform heat transfer, deflection, and stress analysis of a complete mechanical face seal assembly. The basis of the program is a finite-element module which is supplemented by an iteration slope for the consideration of the mutual influence of gap pressure distribution and deformations.

Contrary to the analyses presented before, for the numeric computations both the frictional forces developing at solid contacts and the viscous shear of the fluid in the gap are considered. As the velocity gradient will be important in the narrow

*SEALHDLN = Seal Heat Transfer and Deflection Linear Analysis, MSTI = Mechanical Seal Technology Inc., USA [5]. gaps considered here, the resulting shear stresses and tangential forces depend on the local gap height, the viscosity of the fluid and the sliding speed

$$
M=\int_{A} f \cdot p_{\text {cont }}(r) \cdot r \mathrm{~d} A+\int_{A} \tau\left(h_{\mathrm{G}}, \eta, v\right) \cdot r \mathrm{~d} A
$$

Computations with rectangular seals from ht-plastics show that even at low speeds the temperature in the gap significantly increases in relation to the ambient temperature (Fig. 7). At $4500 \mathrm{r} / \mathrm{min}$ and a pressure of $3.0 \mathrm{MPa}$ the temperature difference is more than $110 \mathrm{~K}$. When the seal slides against the shaft the largest portion of friction heat is dissipated by heat conduction through the transmissions shaft. Another part is transduced by the oil into the housing albeit to a lesser extent due to the laminar fluid flow in this zone. With plastic materials the heat transfer through the seal is comparatively small because of the poor thermal conductivity.

The temperature distribution in the system changes substantially when the simulation is run with metallic seal materials. The maximum temperature and the temperature gradient in the shaft are significantly lower. About two-third of the generated friction power is dissipated through the seal and the remainder through the shaft. At $4500 \mathrm{r} / \mathrm{min}$ and a pressure of $1.5 \mathrm{MPa}$ the maximum temperature exceeds the inlet oil temperature of $80^{\circ} \mathrm{C}$ by not more than $42 \mathrm{~K}$. 


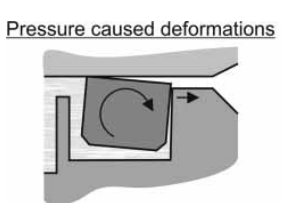

FE calculation on deformations Scale for deflection: 500

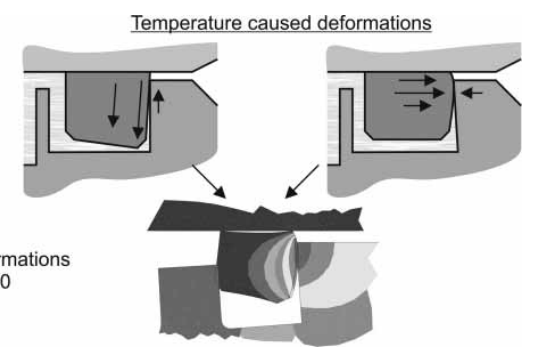

Fig. 8 Pressure and temperature caused deformations at the seal and the shaft

As is the case for mechanical face seals there are typical mechanically and thermally induced deformations of seal and shaft with rectangular seal rings. However, there is a superimposed influence from the contact between the seal and the housing (Fig. 8). The seal is twisted in clockwise direction by the forces resulting from fluid pressure, thereby forming a slightly convergent sealing gap with the counterface on the shaft. In contrast, the gap between the housing and the seal circumference is divergent.

Pressure induced deformations of the shaft are usually negligible, unless it would be hollow with a thin wall. Then, the factor $K_{\mathrm{G}, \mathrm{F}}$ would decline.
The frictional heating from the face of the seal causes it to expand both in axial and in radial direction, resulting in two modes of deformation: on one hand the radial expansion at the face twists the seal ring cross-section, and for usual face seals in the counter clockwise sense. However, due to the radial constraint by the contact between seal ring outer diameter and the housing, the rotation is clockwise for rectangular sealing rings. On the other hand, the seal face becomes slightly conical and convex through the axial expansion.

The effects of the deformations on the temperature and the load within the sealing gap are depicted in Fig. 9 for the investigated seal ring geometry. At low speeds the seal contacts the shoulder of the shaft groove all the way from the seal ring inner diameter $\left(r_{\mathrm{i}}\right)$ to the outer diameter of the shaft $\left(r_{\mathrm{S}}\right)$. The maximum contact pressure occurs near the edge between shoulder and shaft outer diameter.

With increasing speed and frictional heating the temperature in the contact area rises while the maximum contact pressure moves inside from the edge. At the same time, pressure on the inner diameter is relieved and the maximum pressure rises as the real contact area diminishes. At the maximum speed
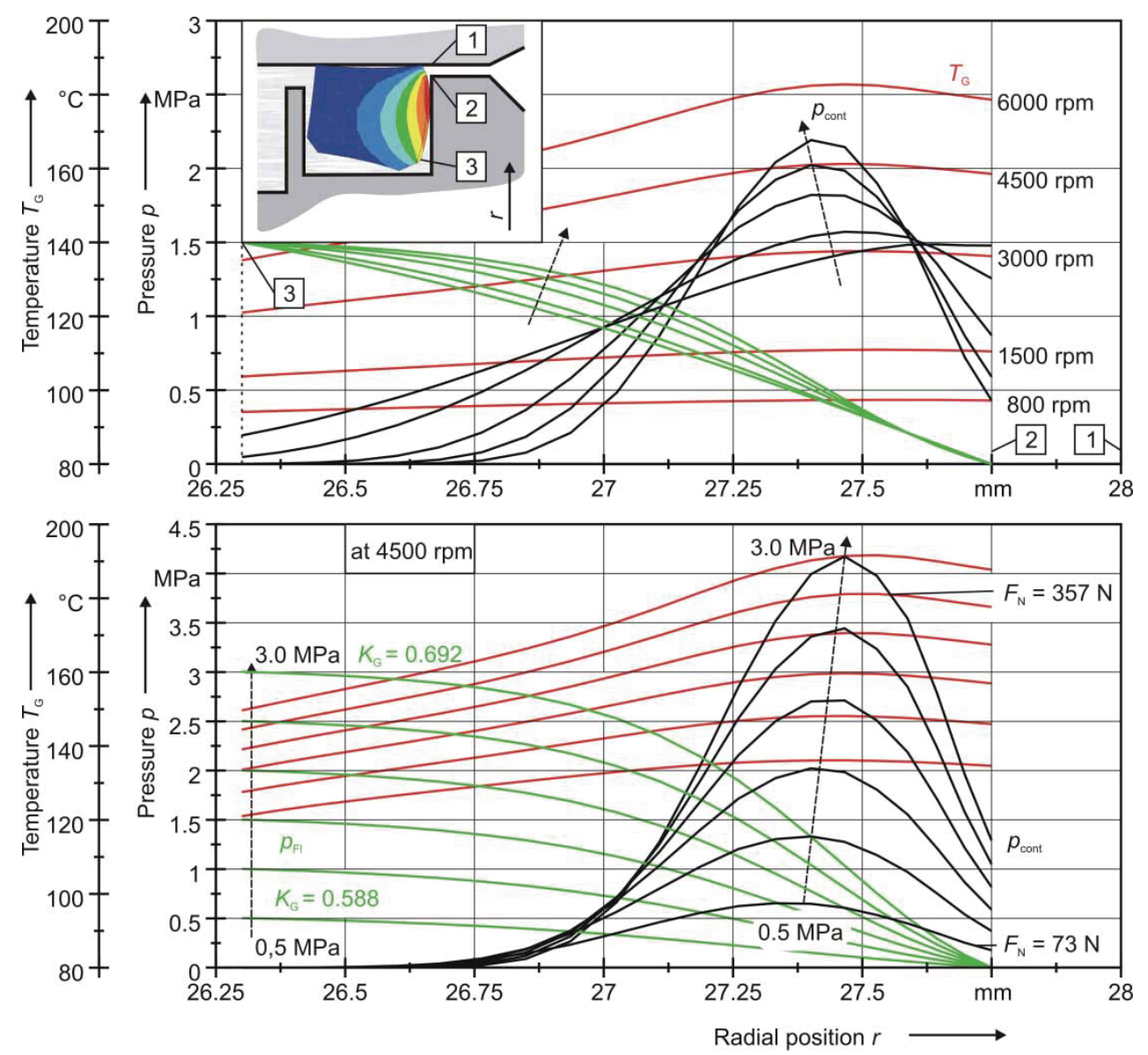

Fig. 9 Calculated face pressure and temperature. Top: at different speeds, bottom: at different pressures 
of $6000 \mathrm{r} / \mathrm{min}$ the real contact is only $1 \mathrm{~mm}$ wide although the nominal length of the contact is nearly twice. However, the slope of the contact pressure distribution declines due to the hydrostatic load relief provided from the pressurized oil that penetrates into the convergent gap from the inner diameter $\left(K_{\mathrm{G}}=\right.$ 0.663 ); this means, that the total resulting radial force carried by the sealing contact decreases at higher speeds.

If the sealed pressure increases at constant speed the pressure peak shifts towards the outer diameter. The pressure related deformation has a more significant relieving effect than temperature; as a result, the total normal force and the friction torque increase less than proportional to the sealed pressure.

As mentioned before, a totally different behaviour is expected for seals from grey cast iron. The centre of the contact pressure distribution also shifts outward when the friction induced temperature increases, but, due to the higher stiffness of the material, deformations do not suffice to form a gap geometry with significant load relief.

In summary, the simulations reveal a strong interaction between mechanical and thermal deformations, sealing gap geometry, fluid pressure profile, contact forces, friction, and heat generation. This has a positive effect on the operation of seals made from ht-plastics as high fluid pressures are partially compensated by hydrostatic forces due to the resulting converging gap geometry, provided sliding is restricted to the axial face. In comparison, the contact forces and friction losses of grey cast iron seals are expected to grow more pronouncedly with sealed fluid pressures.

The high sliding surface temperatures of seals from ht-plastics have both advantages and disadvantages. It is unfavourable that both the liquid which is to be sealed and the sealing ring are exposed to high thermal stresses. It is an advantage, though, that fluid viscosity within the gap and thus viscous shear decline.

\subsection{Leakage}

In sealing systems with rectangular seals, there are several parallel leakage paths. Apart from the axial sealing contact there is the radial contact at the circumference as well as the joint.

Knowing the detailed geometry, the pressure profile, the temperatures and the viscosity and the geometry of the joint, an estimate of the respective leakage shares can be obtained with simple analytical computations based on the Reynolds equation for the contacting faces and Bernoulli equations for the joint. Obviously, the leakage through the joint dominates by far. The amount of leakage passing the seal at the circumference and the face is almost negligible.

Because of the abrupt changes in the channel width and flow direction, more accurate results for the flow through the joint can be achieved with the numerical methods of computational fluid dynamics, however, at the expense of considerable computation times.

\subsection{Measurements}

An extract of extensive experimental investigations is presented in the following chapter. All data are based on a statistical evaluation of at least six tests. A standardized running-in procedure had to be observed before measurements were taken, as there was an excessive spread initially.

Results for PAI A as a typical example for ht-plastics are shown in Fig. 10. The shaded areas indicate the range for all tests after run-in, the additional bars mark the total range for all test with this material including the run-in period.

Mostly for rectangular seals out of ht-plastics the friction torques as well as the gap temperatures increase during the run-in period as the sliding surfaces increasingly conform to each other. For almost all investigated seal types the friction torque decreases noticeably with speed and starts to rise again only slightly after passing a minimum. This trend can be attributed to several effects. Firstly, one may expect the coefficient of friction for the solid contact or the boundary layers to decrease. Secondly, the temperature increase reduces oil viscosity and viscous drag in the fluid film. Finally, the thermomechanical deformations cause the resulting force from the fluid pressure in the gap to increase and thereby the normal force transmitted in the sealing contact to decrease.

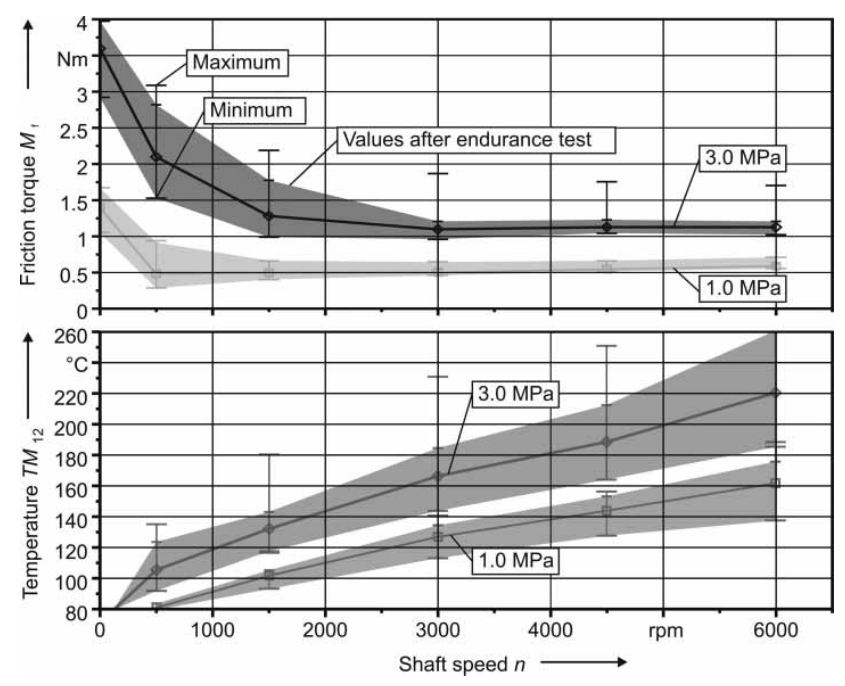

Fig. 10 Measured friction torque and gap temperatures with material PAI A 


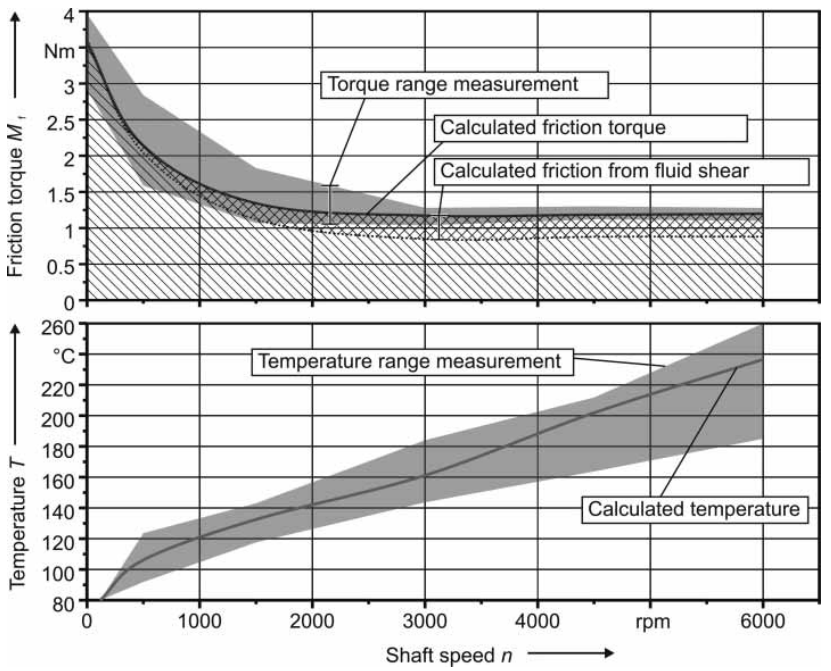

Fig. 11 Comparison of friction torque measurements and calculations

Additionally, there may be hydrodynamic effects due to geometrical imperfections such as waviness and roughness.

When comparing measurements and simulation results in Fig. 11 it becomes evident that these considerations are valid. The friction coefficient used for the computation has been determined empirically whereas the viscous drag contribution is calculated based on theoretical considerations.

\subsubsection{Operation limits}

The operation limit of rectangular seals from grey cast iron is linked to the stability of the separating lubricating film in the sliding contact. If this film breaks down, severe wear occurs and the sealing system is destroyed within a short time.

The mechanisms that define the operation limits of rectangular seals from ht-plastics have not been investigated yet. Obviously, the critical point is the temperatures in the contact zone. In order to determine the maximally permissible temperature of the individual materials, the load on run-in seals and thus the contact temperature were increased in steps until failure.

A typical end of such a test with sealing ring destruction is presented in Fig. 12. The seal failure was indicated when the shaft speed was increased to $7000 \mathrm{r} / \mathrm{min}$ (approximately $19750 \mathrm{~s}$ after the start of the test).

Although the temperature at the outside measuring location $T M_{1}$ had already stabilized, at $T M_{2}$ the temperature was still growing. Shortly thereafter, the friction torque rose sharply and the temperature increase at the seal face accelerated.

This repeatedly observed failure scenario suggests that the sealing ring material in the dynamic sealing zone melts or softens to an extent that a layer close to the surface yields. The resulting conformal profiles prevent oil from penetrating into the gap, leading in turn to higher temperatures. This vicious cycle ends in a thermal destruction of the seal within a few seconds.

In Fig. 13, the operation limits of ht-plastics determined in the tests are compared with their respective glass transition temperatures. It is interesting to note that not reinforced PEEK A can still be used almost $60 \mathrm{~K}$ above its glass transition temperature. Reinforced with glass and carbon fibres, its operation limit is augmented to $240^{\circ} \mathrm{C}$. This temperature, however, is still far below the crystalline melting temperature of $335^{\circ} \mathrm{C}$.

Therefore, both PEEK-compounds could not withstand the limiting temperatures of PAI A or PAI $\mathrm{B}$, which exceed $300{ }^{\circ} \mathrm{C}$. Their real limits could not be determined because they would go beyond the thermal stability limits of commonly used transmission oils.

\subsection{System optimization}

The paramount aim is to minimize the friction loss of a rotating connection by choosing a proper design. The friction torque at a given speed results from the integral of tangential stresses acting in the dynamic sealing face, both from solid contact and fluid shear. It depends on the effective radii, the lubrication situation, the size of the contact area, the contact pressure, the friction coefficient for boundary or solid contact, the fluid viscosity, and the gap width. In most cases, the friction torque from solid contact will prevail

$$
M_{\mathrm{F}}=\int_{F_{\mathrm{T}}} r \mathrm{~d} F_{\mathrm{T}}=\int_{A} r \cdot \mu \cdot p_{\text {cont }} \mathrm{d} A
$$




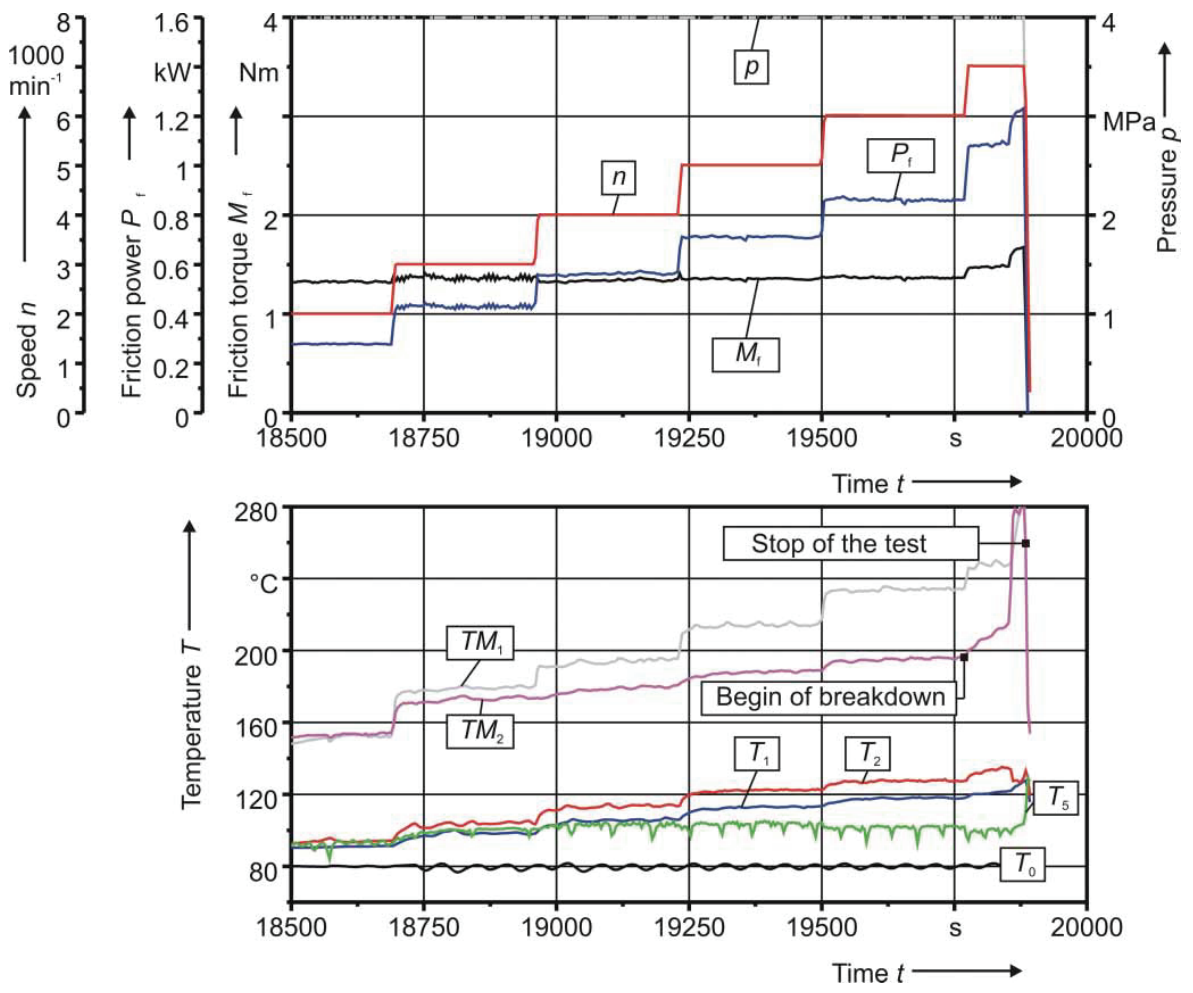

Fig. 12 Operation limit test with seal failure

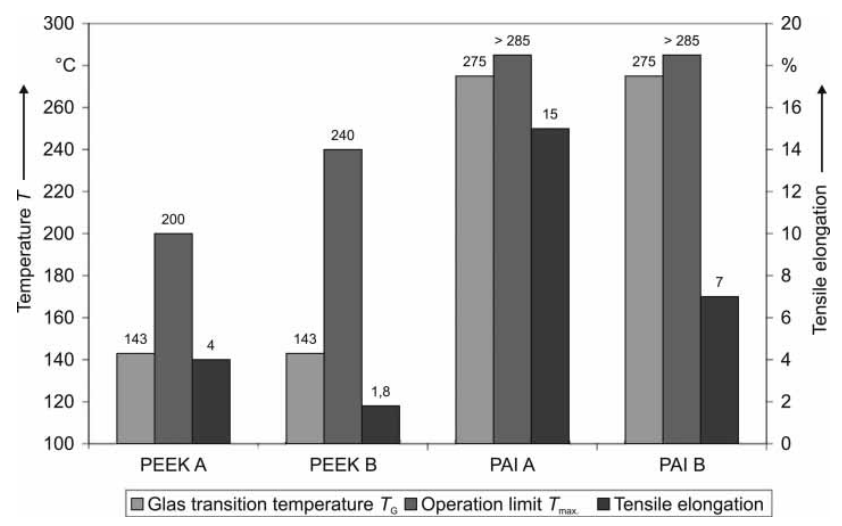

Fig. 13 Comparison of operation limits of ht-plastics

Thus, there are different possibilities for a reduction in the friction torque:

(a) reduction of the resulting normal contact force $p_{\text {cont }} \cdot \mathrm{d} A$ through hydrostatic or hydrodynamic load reduction;

(b) reduction of the apparent friction coefficient by

(1) macroscopic or (2) microscopic features, which enhance micro-elastohydrodynamics with respect to boundary lubrication.

\subsubsection{Hydrostatic load reduction}

The most straightforward method to reduce the normal force on the sealing contact is to diminish the pressurized area on the opposite side of the seal. For rectangular seals which rotate with the shaft this means to reduce the width. If the sliding motion occurs at the axial seal face the radial height of the seal cross-section needs to be minimized. However, there are limitations, e.g. with respect to the mechanical stability and stiffness of the seal body. For this reason it is preferable to provide hydrostatic chamfers or pockets, which are open to the pressurized fluid, Fig. 14, and extend over the whole circumference with the exception of the joints. They need to be dimensioned in such a way that the contact pressure in the remaining circular sealing face and the leakage stay within acceptable limits. Obviously, geometry imperfections, especially eccentricities, need to be considered in order to avoid an intersection between the pockets and the gap between shaft and housing which would create an open leakage path. The depth of the pockets has to be adapted to the expected amount of wear.

With hydrostatic pockets or chamfers the friction torque of the investigated seals can be expected to decline by more than 30 per cent. As a consequence, the temperature in the dynamic sealing contact is predicted to decrease by up to $30 \mathrm{~K}$. These computational results were confirmed by measurements with machined seal rings. The improvements partially exceeded the theoretical predictions. As a result of the lower temperature of the whole system the leakage rate dropped as well due to the dominating leak through the seals joint. 

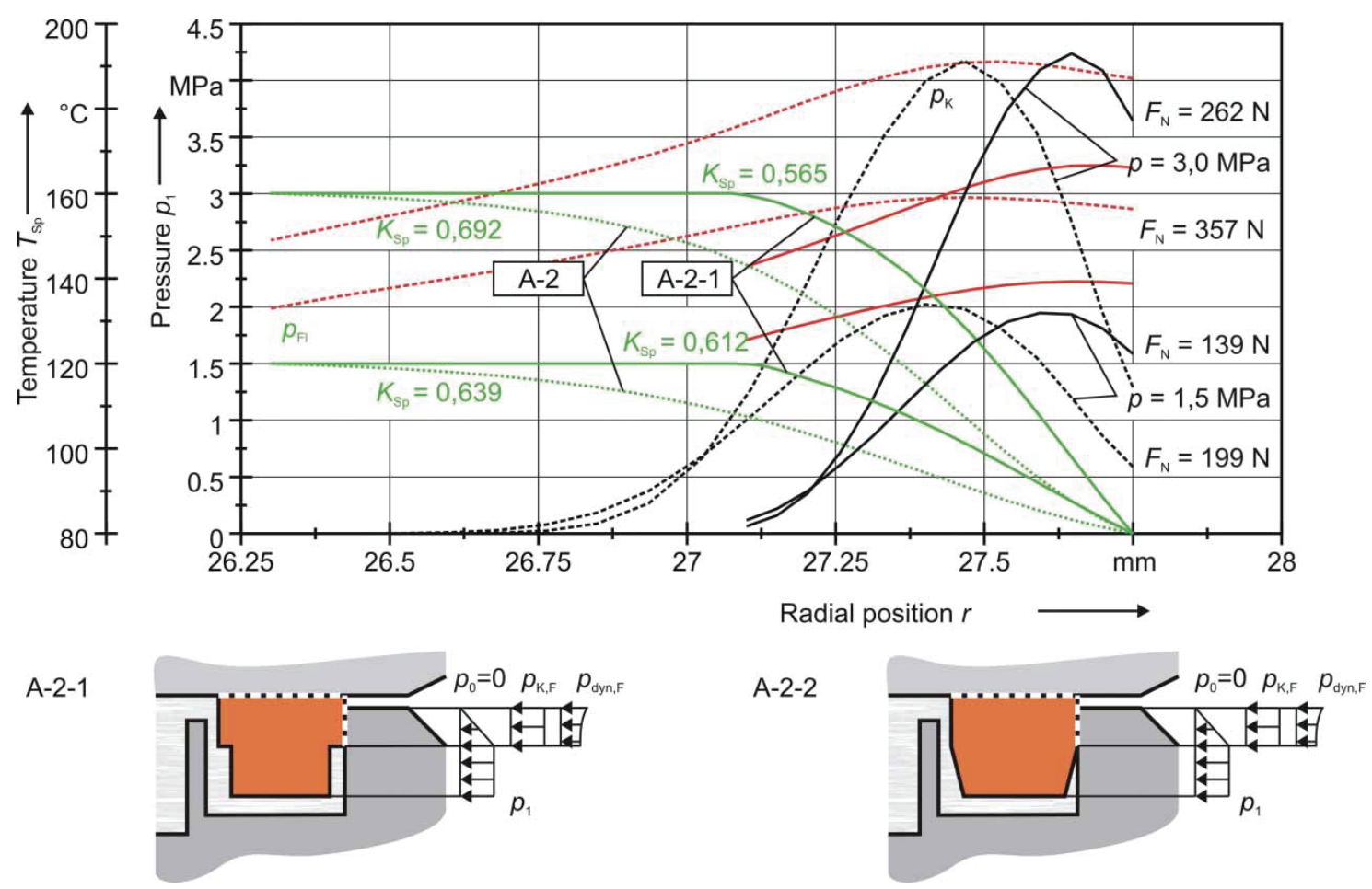

Fig. 14 Calculated face pressure and temperature for standard seals and seals with hydrostatic load reduction

\subsubsection{Hydrodynamic load reduction}

Hydrodynamic patterns are often successfully used in mechanical face seals in order to enhance lubricant film formation in the sealing contact. The basic principle is always to drag fluid in the circumferential direction into channels with declining cross-section. This causes the fluid pressure to rise locally and to carry part of the normal load. Thus the interaction between solid surfaces decreases, most notably the friction.

Various features that have been devised and tried so far for mechanical face seals were considered for rectangular seals.

As those have no preferred orientation for mounting, unidirectional features had to be excluded. As a first try to gain insight, features with a sickle shape according to Fig. 15 were investigated. The sharp end of the pocket was positioned at the calculated contact pressure (maximum).
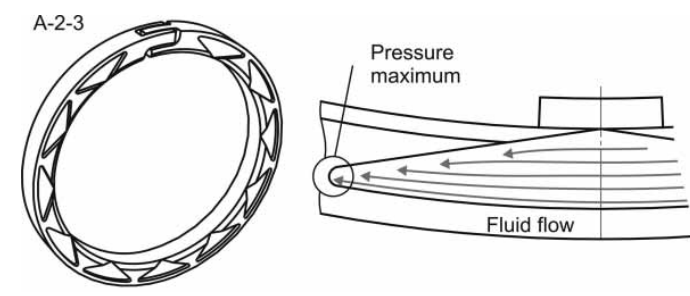

Fig. 15 Feature for hydrodynamic load reduction
As the pocket is open to the pressurized fluid, the seal ring is relieved hydrostatically and hydrodynamically at the same time. In order to estimate the effectiveness of the hydrodynamic relief, it is useful to examine the measured torque reduction in dependence with sliding speed. For this purpose, the dynamic friction torques were set in proportion to the start-up torques at standstill (Fig. 16).

Evidently, both at $1.5 \mathrm{MPa}$ and at $3.0 \mathrm{MPa}$ a hydrodynamic contact force relief is effective on top of the hydrostatic one, resulting in a more pronounced friction torque reduction provided the speed is high enough. Once again, the leakage is lower than for plain seals, as the influence of frictional heating on viscosity and the leak through the joint prevails. For seals subject to high thermal stress at elevated sliding speeds this may well be a design modification worth to be pursued.

It should be noted, that friction drops with speed for the hydrostatic features as well, albeit to a lesser extent than for the hydrodynamic ones. As pointed out earlier, this observation may partly be attributed to the decline in fluid viscosity and coefficient of boundary friction as well as the change in the pressure profile in the fluid due to a more converging gap profile; however, there may also be some hydrodynamic effects even without intentional hydrodynamic features. Those result from the unavoidable waviness of the surfaces as well as from roughness. 

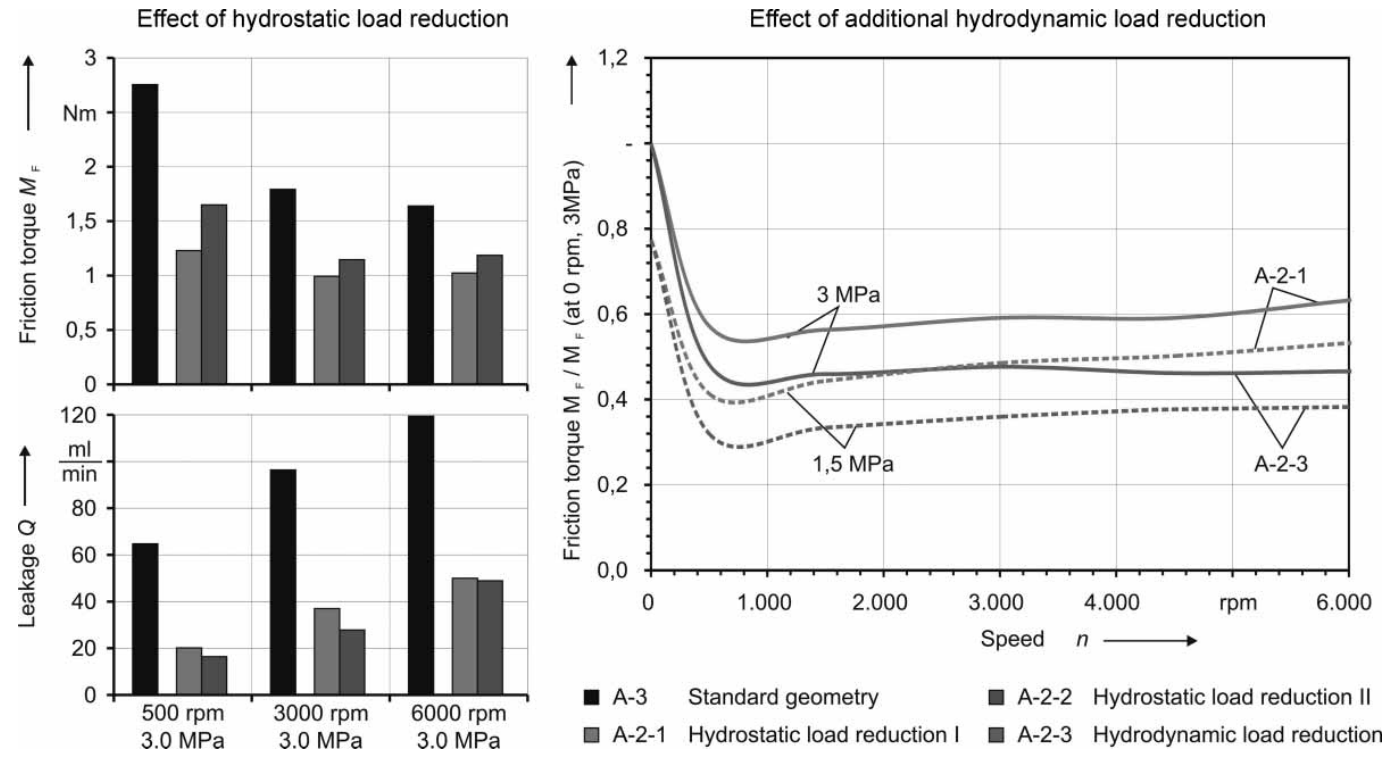

Fig. 16 Seal geometry optimization - experimental results (right: normalized)

\section{CONCLUSIONS}

Rectangular seal rings are used in various shapes for rotating connections in automotive transmissions. Significant power losses occur which diminish the efficiency. Temperatures up to $300{ }^{\circ} \mathrm{C}$ can destroy the seal itself as well as the pressurized oil.

For cost and design reasons grey cast iron rings are more and more substituted by modern, hightemperature resistant thermoplastics. These materials also exhibit better friction and wear performance.

Friction losses, seal rotation, mechanical, and thermal deformations can be determined by means of analytical and numerical calculations. Such computations give valuable hints for an optimized design.

Power losses of such Seals can often be reduced by more than half using appropriate macroscopic face features, which allow a hydrostatic relief of the seal. Further improvements are achievable with hydrodynamic features, which are known from face seals.

\section{REFERENCES}

1 Kuroki, T., Abe, Y., and Sowa, M. Durability Upgrading and frictional torque lowering of the seal ring used for automatic transmissions. SAE paper 920720, 1992.

2 Nakaoka, S., Kameike, M., Ono, S., and Takeda, T. Seal ring design for high pressure and high shaft velocity. Int. Colloq. Tribol., 2002 13, 2237-2242.

3 Kuroki, T. and Sowa, M. Investigation of leakage phenomena and improvement of sealing performance of seal rings used for rotary shafts of automatic transmissions. SAE paper 910534, 1991.

4 Rogler, H. Untersuchungen zu Betriebsverhalten und Auslegungsgrenzen von Kolbenringdichtungen für die radiale Druckmittelzuführung in umlaufende Wellen mit

Hilfe von Radionuklidmessverfahren. Final report FVAinvestigations nr. 23, paper 55, 1977.

5 Lebeck, A. O. Principles and design of mechanical face seals, 1991 (John Wiley, New York).

\section{APPENDIX}

\section{Notations}

$b$

$f$

$F_{Z}$

$h$

$k$

K

$M$

$p$

$r$

$T$

TM1 TM2

\section{Subscripts}

a

C

cont

dyn

el

F

Fl

fr

G

Gr

i

o

r

$\mathrm{s}$ width (m)

coefficient of friction

centrifugal force $(\mathrm{N})$

high (m)

balance ratio

gap-factor

torque (Nm)

pressure $(\mathrm{Pa})$

radius $(\mathrm{m})$

temperature $\left({ }^{\circ} \mathrm{C}\right)$

temperature measurement points at the seal's face $\left({ }^{\circ} \mathrm{C}\right)$

axial

circumference

contact

dynamic

elastic

face, chamfer

fluid

friction

gap

groove

inside

outside

radial

shaft 